\title{
Changes in Sound Absorption Capability and Air Permeability of Malas (Homalium foetidum) Specimens after High Temperature Heat Treatment ${ }^{1}$
}

\author{
Chun-Won $\mathrm{Kang}^{2} \cdot$ Chengyuan $\mathrm{Li}^{3} \cdot$ Eun-Suk Jang ${ }^{2} \cdot$ Sang-Sik Jang ${ }^{4} \cdot$ Ho-Yang Kang $\mathbb{D}^{4 \dagger}$
}

\begin{abstract}
The changes in sound absorption capability and air permeability of Malas wood after high temperature heat treatment were investigated. The average air permeability of Malas in longitudinal direction after heated under the temperature of $190^{\circ} \mathrm{C}$ during 3 hours was about 23.48 darcys and that of control was about 3.11 darcys. The noise reduction coefficients of Malas specimens were $17 \%$ for treatment and $10 \%$ for control. The means of sound absorption coefficient of specimens in the frequency range of $50 \sim 6,400 \mathrm{~Hz}$ were $42 \%$ for treatment and $17 \%$ for control, respectively.
\end{abstract}

Keywords: heat treatment, air permeability, sound absorption coefficient, Malas

\section{INTRODUCTION}

Solid wood thermal modification has been widely studied over the years (Hill, 2006). In general, thermal modification reduced hygroscopicity and water absorption, thus increasing dimensional stability and decay resistance. However, the information on changes in sound absorption property and permeability of wood after high temperature heating treatment was scare.

Malas wood has been used as interior or exterior materials because of its good hardness, resistance to weathering and relatively good elastic properties. In the case of the wood used as interior materials, the proper sound absorption capability of wood was necessary for good acoustic environment. It was recognized that the sound absorption capability of wood was influenced by airflow resistivity or air permeability that varied according to the sound incident surface structure and pore characteristics (kang et al., 2012; kang et al., 2008; kang et al., 2010; kang et al., 2011; wassilieff, 1996).

Therefore, the purpose of this study was to evaluate effect of high temperature heating treatment on the sound absorption property and permeability of malas wood which was one of widely used wood in southeast Asia.

\footnotetext{
${ }^{1}$ Date Received January 29, 2018, Date Accepted March 8, 2018

A part of this paper was presented at the conference of 9th International symposium of IWoRS in Baly, Indonesia, September 2017

2 Department of Housing Environmental Design, and Research Institute of Human Ecology, Chonbuk National University, Jeonju 54896, Republic of Korea

${ }^{3}$ Department of Wood Science and Engineering, Beihua University, China

${ }^{4}$ Department of Bio-based Materials, Chungnam National University, Daejeon 34134, Republic of Korea

$\dagger$ Corresponding author: Ho-Yang Kang(e-mail: hykang@cnu.ac.kr, ORCID: 0000-0002-0544-0721)
} 


\section{MATERIALS and METHODS}

\subsection{Specimen Preparation}

Malas (Homalium foetidum) lumbers imported from Papua New Guinea were used in this study. The green malas lumbers with $120 \mathrm{~mm}$ in width, $30 \mathrm{~mm}$ in thickness and $1800 \mathrm{~mm}$ in length were heated under the temperature of $190^{\circ} \mathrm{C}$ for 3 hours. From green malas and heat treated malas, five cylindrical log cross sections with $28.9 \mathrm{~mm}$ in diameter and $10 \mathrm{~mm}$ in thickness were prepared. The total quantity of 10 pieces log cross sections were oven dried under the temperature of $100^{\circ} \mathrm{C}$. The average moisture content (MC) of control and heat treated specimens were $6.08 \%$ and $4.12 \%$, respectively. The average specific gravity of control and heat treated specimens were $0.76 \mathrm{~g} / \mathrm{cm}^{3}$ and $0.65 \mathrm{~g} / \mathrm{cm}^{3}$, respectively.

\subsection{Gas Permeability and Pore Size Measurement}

The permeability of specimens was measured by membrane pore size analyzer (Porous Material Incorporated, CFP-1200AEL) according to capillary flow porometry as precious research (kang et al., 2017). The principle of this method was described in ASTM 316-03. The pore structure and permeability were evaluated using liquid and gas flow as a function and the pressure difference. When a wood specimen was soaked in the wet solution, the specimen with different diameter of holes was easily wet because the solution had the low surface tension of $15.9 \mathrm{~N} / \mathrm{m}$. After thoroughly soaked specimen was put into sample chamber, the chamber was sealed as shown in Fig. 1, and then non-reactive nitrogen gas was circulated. The bubble point was first measured at the pore with largest diameter inside which the pressure was the minimum value compared to other pores, that is, at the place to overcome the capillary action of the fluid from gas pressure, as the solution was forcing out. After that, the flow was

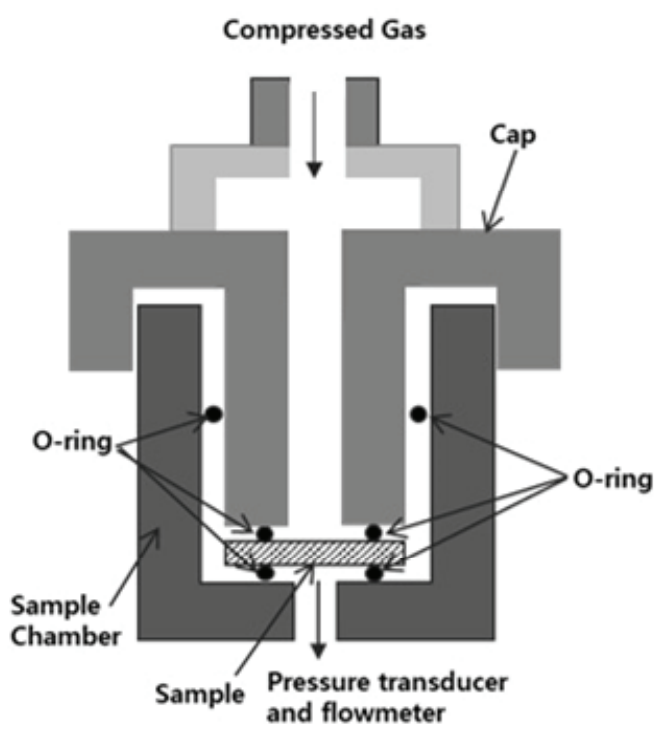

Fig. 1. Diagram Of Sample Chamber.

measuring until all pores was empty as the pressure being increasing. The pressure and flow rate of the gas through the dried specimen were measured although the liquid in all pores was not existence. The gas permeability and pore structure of wood specimen were evaluated from the results. The gas permeability of wood specimen was calculated according to Equations (1) and (2).

$$
v=-(k / \mu)(d p / d x)
$$

where, $v=$ flow rate, $k=$ permeability, $\mu=$ viscosity, $p=$ pressure, $x=$ location

$$
F=v A=-(k A / \mu)(d p / d x)
$$

where, $F=$ flow, $A=$ cross sectional areas

\subsection{Sound Absorption Rate Measurement}

The sound absorption rate of specimen was measured by two microphone transfer function method using impedance tube (B\&K company, kit type 4706), pulse 
analysis equipment and a spectrum analyzer $(\mathrm{B} \& \mathrm{~K}$ company), as precious research (kang et al., 2012). In this study, the variation of sound absorption rate was measured as change of frequency in the range of $50 \sim 6,400 \mathrm{~Hz}$. During measurement, temperature, relative humidity and atmospheric pressure were $25^{\circ} \mathrm{C}, 52 \%$ and $1008.0 \mathrm{hPa}$ for control specimens and $24.6^{\circ} \mathrm{C}, 48 \%$ and $1008.0 \mathrm{hPa}$ for treated specimens, respectively. Moreover, the velocity of sound, air density and acoustic impedance were $346.15 \mathrm{~m} / \mathrm{s}, 1.176 \mathrm{~kg} / \mathrm{m}^{3}$ and $407.0 \mathrm{~Pa} /$ $(\mathrm{m} / \mathrm{s})$ for control specimens and $345.92 \mathrm{~m} / \mathrm{s}, 1.177 \mathrm{~kg} / \mathrm{m}^{3}$ and $407.2 \mathrm{~Pa} /(\mathrm{m} / \mathrm{s})$ for treated specimens, respectively.

\section{RESULTS and DISCUSSION}

\subsection{Change of Pore Structure and Permeability of Specimen}

Capillary flow porometry estimates the constricted pore diameter of a porous material, which is the smallest pore diameter of one flow pathway. This constricted pore may be enlarged by heat treatment as shown in Fig. 2. The pore size distribution as a function of average pore diameter by CFP represent that the pore diameter enlarged and the number of permeable pores in treated wood increased, as compared to control wood.

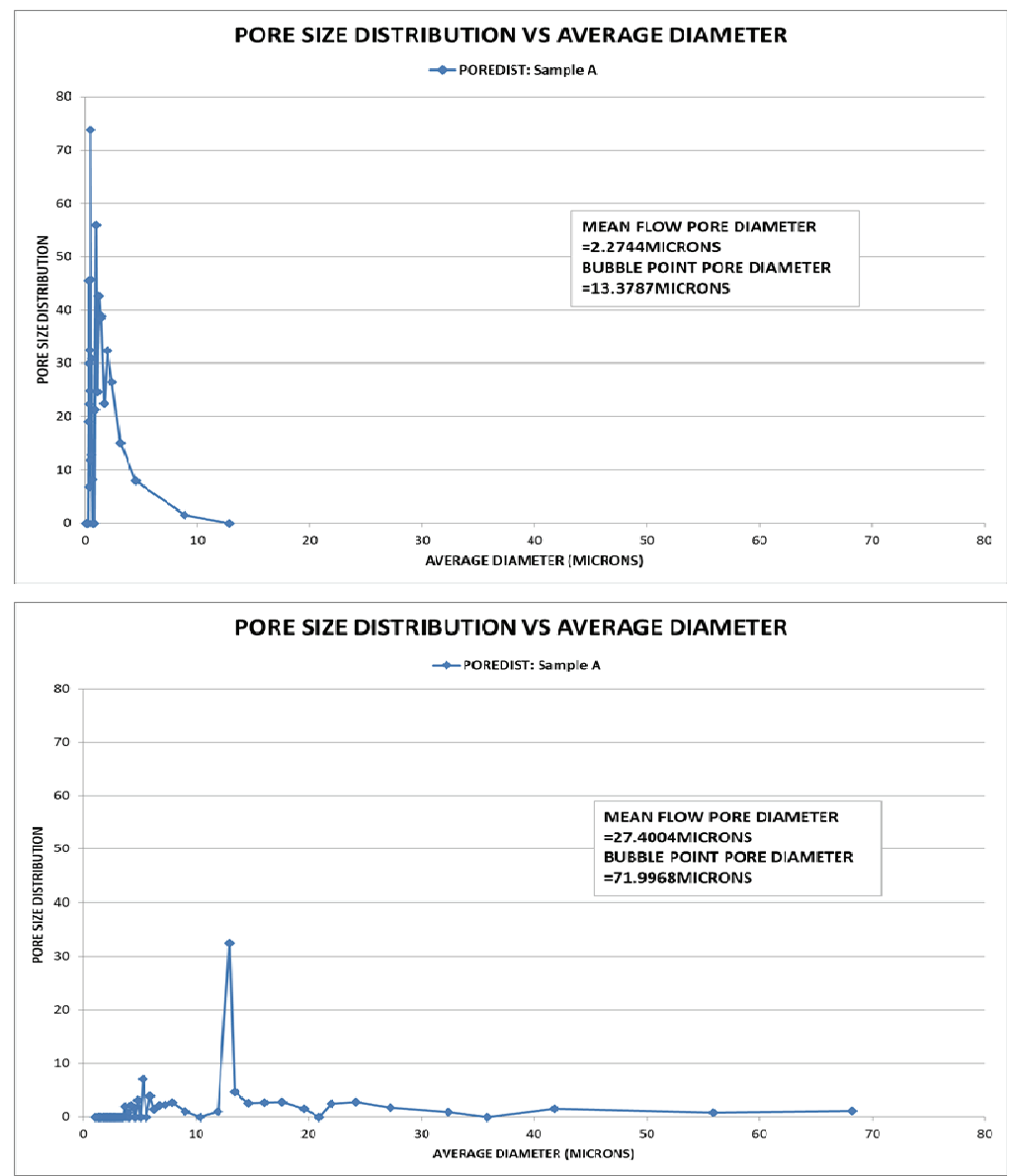

Fig. 2. Typical plots of pore size distribution as a function of average pore diameter of $10 \mathrm{~mm}$ thick malas wood (top: control, bottom: heat treated). 

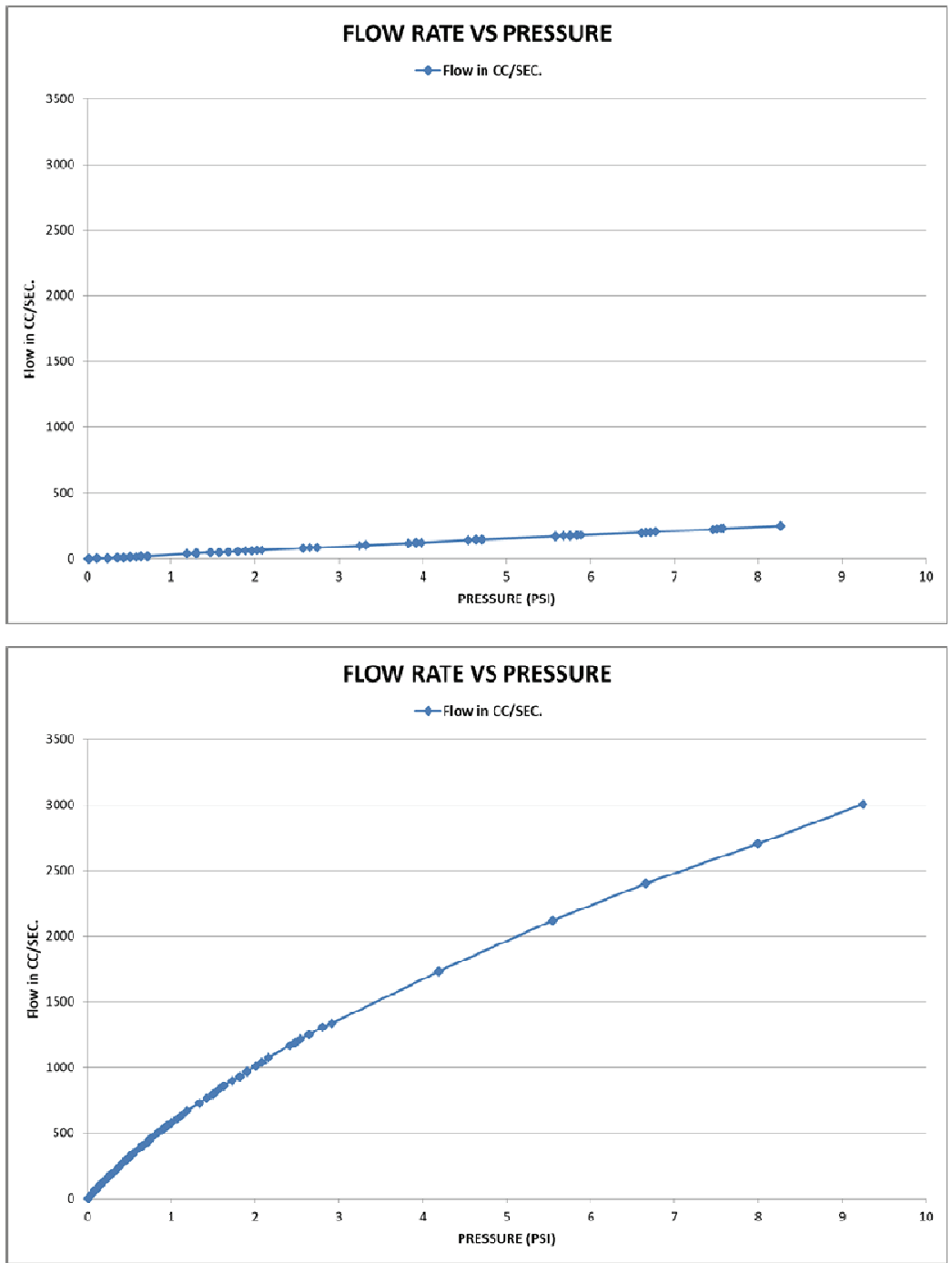

Fig. 3. Typical plots of air flow rate in longitudinal direction vs. pressure for $10 \mathrm{~mm}$ thick malas wood (top: control, bottom: heat treated).

The change of permeability for control and treated specimens is presented in Fig. 3. Average permeability of control specimens was 3.11 darcy while that of treated specimens was 23.48 darcy, which is about 8 times higher than that of control specimens. This trend could be attributed to the flow passageway inside wood after treatment being more and larger than before treatment.

\subsection{Change of Sound Absorption Rate of Specimen}

The sound absorption rates of specimens in the frequency range of $50 \sim 6,400 \mathrm{~Hz}$ are shown in Fig. 4.

As showed in Fig. 4, the sound absorption rates of treated specimens showed higher values than those of control specimens in almost all frequency range. The 

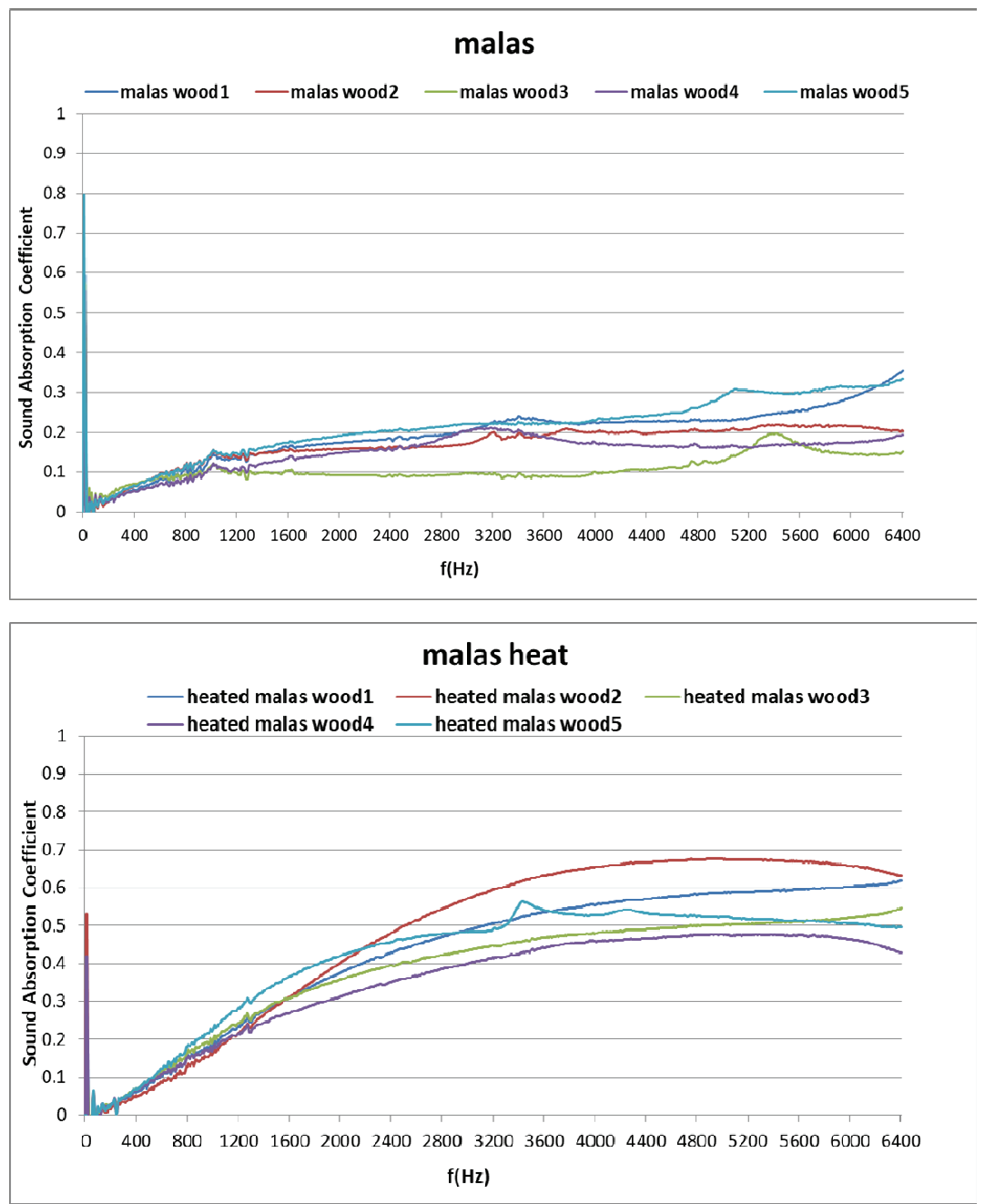

Fig. 4. Relationship between sound absorption coefficient and frequency for $10 \mathrm{~mm}$ thick malas wood (top : control, bottom : heat treated).

difference in sound absorption rates between treated and control specimens became larger with increasing of frequency beginning from $1 \mathrm{kHz}$, reached 2 times in frequency range of nearby $2 \mathrm{kHz}$ and nearby $6 \mathrm{kHz}$. It indicates that the sound absorption rate of treated specimens is increasing with increasing of frequency, which is a typical characteristic of porous sound absorber. This trend could be accounted for there being more pores and larger flow passageway in wood due to the inclusions inside wood such as gum, carbohydrate, etc. being melted and discomposed out during treatment. It can be inferred that the sound absorption rate of treated specimens was significantly increased because the flow of the air as the medium transferring the energy of sound wave was increased due to improved permeability during heat treatment.

The NRC (noise reduction coefficient, mean value of sound absorption coefficient at the frequency of 250 , 
$500,1,000$ and $2,000 \mathrm{~Hz}$ ) showed a value of 0.17 for treated specimens and 0.10 for control specimens, which indicated that the NRC of treated specimens is improved by 70 percent compared to that of control specimens. It is advised that to apply the heated malas wood as environmentally friendly sound absorption materials is possible.

\section{CONCLUSION}

In order to evaluate changes in sound absorption property and permeability, the sound absorption rate and permeability of heated malas wood were measured before and after heat treatment in this study. The results of this study were as follows:

1. The sound absorption rate of treated specimens showed high value in almost all frequency range. Thus malas wood after heat treatment was could be considered as sound-absorbing materials because its mean value of sound absorption rate in the frequency range of 50 6400 $\mathrm{Hz}$ was over $40 \%$.

2. The permeability of heated malas wood was increased by about 8 times compared to that of control.

3. The pore diameter of heated malas wood was enlarged compared to that of control.

\section{ACKNOWLEDGMENT}

This research was supported by Basic Science Research Program through the National Research Foundation of Korea (NRF) funded by the Ministry of Science and ICT (NRF-2017R1A2B4012538).

\section{REFERENCES}

ASTM 316-03 2011. Standard test methods for pore size characteristics of membrain filters by bubble point and mean flow pore test. American society for testing and materials.
Hill, C.A.S. 2006. Wood modification-chemical, thermal and other processes. John Wiley and Sons Ltd., Chichester.

Kang, C.-W., Choi, I.-G., Gwak, K.-S., Yeo, H.-M., Lee, N.-H., Kang, H.-Y. 2012. Changes of sound absorption capability of wood by organosolv pretreatment. Journal of the Korean Wood Science and Technology 40(4): 237-243.

Kang, C.-W., Kang, W., Chung, W.-Y., Matsumura, J., Oda, K. 2008. Changes in anatomical features, air permeability and sound absorption capability of wood induced by delignification treatment. Journal of the Faculty of Agriculture, Kyushu University 53(2): 479-483.

Kang, C.-W., Kim, G.-C., Park, H.-J., Lee, N.-H., Kang, W., Matsumura, J. 2010. Changes in permeability and sound absorption capability of yellow poplar wood by steam explosion treatment. Journal of the Faculty of Agriculture, Kyushu University 55(2): 327-332.

Kang, C.-W., Lee, Y.-H., Kang, H.-Y., Kang, W., Xu, H.-R., Chung, W.-Y. 2011. Radial variation of sound absorption capability in the cross sectional surface of yellow poplar wood. Journal of the Korean Wood Science and Technology 39(4): 326-332

Kang, C.-W., Oh, S.-W., Lee, T.-B., Kang, W., Matsumura, J. 2012. Sound absorption capability and mechanical properties of a composite rice hull and sawdust board. J Wood Sci 8: 273-278.

Kang, C.-W., Park, H.-J., Jun, S.-S. 2012. Sound absorption capability and bending strength of miscanthus particle based board. Journal of the Korean Wood Science and Technology 40(1): 38-43.

Kang, H.-Y., Lee, W.-H., Jang, S.-S., Kang, C.-W. 2017. Polyethylene glycol treatment of Han-ok round wood components to prevent surface checking. Bioresources 12(2): 4229-4238.

Wassilieff, C. 1996. Sound absorption of wood-based materials. Applied acoustics 48(4): 339-356. 